Published in: International Journal of Fatigue, 29 (2007) 565-574

\title{
An effective method to investigate short crack growth behaviour by reverse bending testing
}

\author{
N. Gao ${ }^{a, *}$, M. W. Brown ${ }^{b}$, K. J. Miller ${ }^{\text {b }}$, P. A. S. Reed ${ }^{a}$ \\ ${ }^{a}$ Materials Research Group, School of Engineering Sciences, University of \\ Southampton, Southampton, SO17 1BJ \\ ${ }^{\mathrm{b}}$ Department of Mechanical and Process Engineering \\ University of Sheffield, Sheffield S1 3JD
}

\begin{abstract}
A reverse bending rig has the advantage of relatively cheap construction compared with servo-controlled machines, and its robustness and reliability make it ideally suited to long-term testing programmes. In this paper, the details of the mechanical mechanism of a bending rig, the methods of its strain measurement and stress-strain analysis have been presented. A series of tests has been carried out to investigate short crack growth behaviour of AISI type 316 stainless steel under creep-fatigue conditions at $550^{\circ} \mathrm{C}$. The advantage of this type of test allows a comparison to be made, on one specimen, of the influence of both tensile and compressive hold periods on crack growth behaviour. It has been shown that predominantly intergranular long cracks form on the tensile side and transgranular short cracks on the compressive side and these are a prominent feature between $0.9-2.5 \%$ strain range.
\end{abstract}

Key words: Creep-fatigue, Short crack, Crack coalescence

\footnotetext{
* Corresponding author. Tel.: +44-2380-593396; fax: +44-2380-593016

E-mail address: n.gao@soton.ac.uk
} 


\section{Introduction}

Materials subjected to high temperature service are usually exposed to complex strain-time histories and experience differing damage modes. Creep damage, which is a time-dependent process, depends primarily on the history of stress and temperature applied to the component; whereas fatigue damage is generated by the cyclic stress and depends primarily on time-independent plastic strain. The imposition of one form of damage is also known to influence the other. When the two damage components act in a combined manner, a creep-fatigue interaction develops $[1,2,3]$. The basic reason for the creep-fatigue effect can best be understood by detailed consideration of the stress-strain pattern involved during cycling with a tensile hold period. During the tensile hold period, stress relaxation occurs at a range of strain rates, similar to those encountered during creep testing, and produces an additional amount of tensile strain to that produced from fatigue cycling. Although this additional strain, which is given by the amount of stress relaxation divided by Young's modulus, is less than $0.1 \%$ per cycle, it has a drastic effect on the life [4].

Many service conditions result in creep-fatigue damage. For example, the current high price of fossil fuels and the increased use of large nuclear plant for base-load electric power generation have resulted in increased shift operation of fossil-fired plant. Between start-up and shut-down there is a period of on-load running. The material at the surface of a stress concentrating feature may be at constant strain during this period, and stress relaxation will take place by creep. Similar types of situation arise also in steam turbine components, pressure vessels and gas turbines. To design any of these components for satisfactory operation requires an understanding of the mechanisms which occur in the creep-fatigue processes. In particular, the creepfatigue endurance of the type 300 series austenitic stainless steels has received a great 
deal of attention because of their various applications in the power generation industry and particularly the nuclear industry.

In 1961 Forrest and Penfold [5] first reported on a reverse bending fatigue machine which they had developed for thermal fatigue testing. A bar specimen of rectangular cross-section was bent through a predetermined angle of deflection, producing alternating strain on the top and bottom surfaces of the specimen. In 1963 Forrest and Armstrong [6] reported on strain controlled fatigue tests performed on Nimonic alloys using a number of these reverse bending machines. A large number of machines were later built within the UK for the testing of power plant materials $[7,8,9]$. Subsequently there have been substantial developments in uniaxial push-pull fatigue testing and most tests are now performed on such machines. Until now, most information from reverse bending tests are related to long crack investigation and there is still limited information available on short crack investigation using reverse bending rigs in the literature, although reverse bending machines are of particular benefit in creep/fatigue tests $[10,11,12]$. Fully reversed bending creep-fatigue tests can be performed on a displacement controlled high temperature bending rig. Its relatively cheap construction compared with servo-controlled machines together with its robustness and reliability make it ideally suited to long-term testing programmes. When a hold time is introduced into a bend specimen, one side is subjected to a tensile hold period, while the opposite side experiences a compressive hold period. Thus this type of test allows a comparison to be made, on one specimen, of the influence of both tensile and compressive hold periods on crack growth behaviour $[13,14]$

This paper first addresses the mechanical mechanism, the methods of strain measurement and the stress-strain analysis of the reverse bending rig. Then, an 
investigation of short crack growth behaviour in AISI type 316 stainless steel under creep-fatigue conditions is presented, which shows that reverse bending testing is an effective method to study both tensile and compressive effects on this failure phenomenon simultaneously.

\section{Reverse bending rig}

\subsection{Mechanical mechanism of the bending rig}

A schematic view of the mechanical mechanism of the bending rig is shown in Fig. 1. A full description of the rig can be found in Ref. [15,16], and only a brief introduction is presented here. The test specimen was clamped by two horizontal cross shafts made of type 316 stainless steel using removable clamping plates. It was strained in pure bending by rotation of the cross shafts about their axes. The development of a net tensile stress in the specimen during bending was avoided by allowing one of the cross shafts to move horizontally in slots as well as to rotate. Both cross shafts were connected to cross beams by means of a pair of lever arms. Two loading arms were fixed on the cross beams at one end of the specimen and connected via bearings eccentrically on two pulleys on the other end. The drive for the rig was provided by a D. C. motor, having a 2,000 r.p.m. maximum speed, connected to one of the pulleys through a reduction gear box, and this movement was then transferred to the second pulley via a chain. Therefore, when the same eccentricity was provided on each pulley, equal and opposite angular movements can be applied to a specimen. To prevent accidental damage to the machine in the case of a specimen fracture, a safety microswitch was set on one end of the cross shaft which would cut off the power supply and stop the rig. A multifunction digital timer, designed to fulfil the majority of time relay requirements on the control panel of the rig, permitted dwell 
periods from 9.99 seconds to 99.9 hours thereby making wide-ranging creep-fatigue tests possible.

\subsection{Strain measurement and furnace}

The specimen bending moment was obtained from a load cell on one of the vertical loading arms. The load cell output readings in the form of DC voltage were monitored continuously by a digital multimeter and a chart recorder. Hysteresis loops were also plotted at intervals throughout the tests. The plotter was calibrated periodically with a digital voltmeter. Control of specimen strain was achieved by adjusting manually the eccentric radii of both pulleys, which were fitted with scales to record the required values of angle of bend $\phi$ for different strain amplitudes, where

$\phi=\operatorname{Sin}^{-1}$ [ (Eccentric radius of pulley) / (Length of moment arm) ]

Here the eccentric radius set on the pulley is equal to the amplitude of vertical displacement in either upward or downward directions, and the length of the moment arm is the distance from the centre of the lever arm bearings to the centre of the cross beam. A full description of the strain measurement and bend geometries can be found in Ref. [15]. The displacement signal from a linear displacement transducer was recorded continuously by a digital multimeter and a chart recorder and was drawn periodically by an X-Y plotter. The values of strain for the specimen can be calculated by a simple geometrical relationship equation from the values of angle of bend.

The specimen was heated by a horizontally mounted split $5 \mathrm{~kW}$ electric furnace. The furnace was surrounded by sheets of stainless steel inlaid with insulating material to 
minimise heat loss. A thermocouple, sheathed in a stainless tube, was fixed to the specimen to monitor continuously the temperature of the furnace. The thermocouple was connected to a microprocessor based Eurotherm controller which can automatically monitor and maintain the set temperature, and display the measured value of the temperature in digital form. On average, the temperature along the specimen length was uniform and the difference between separate thermocouple readings and the Eurotherm readings was within $\pm 3^{\circ} \mathrm{C}$.

\subsection{Stress-strain analysis}

Cylindrical specimens with a total gauge length of $153 \mathrm{~mm}$ and a diameter of $10 \mathrm{~mm}$ were employed. The clamping zones at both ends of the specimen were made flat in order to hold the specimens rigidly in the rig grips. Consider a round cross-section specimen subjected to a reversed bending moment $M$ and assume that the original plane sections remain planar under bending. The amplitude of surface strain at a distance $y$ from the neutral axis of the specimen is given by

$$
\varepsilon=\frac{2 \not y}{L}
$$

where $\phi$ is the angle of bend and $L$ is the specimen gauge length. The maximum surface strain for a round bar of radius $r$ is, therefore

$$
\varepsilon=\frac{2 \phi r}{L}
$$


The total bending moment, taking into account the symmetrical contribution to the bending moment of the sections above and below the neutral axis is

$$
M=2 \int_{0}^{r} 2 \sigma y \sqrt{r^{2}-y^{2}} d y
$$

Because of the stress-strain behaviour, the material follows a power law

$$
\sigma=k(\varepsilon)^{n}
$$

expressing the stress in terms of its equivalent strain from equations (2) and (5) gives

$$
M=4 k\left(\frac{2 \phi}{L}\right)^{n} \int_{0}^{r} y^{1+n} \sqrt{r^{2}-y^{2}} d y
$$

Substitution of $\operatorname{Sin} \theta=(y / r)$ in equation (6), the maximum bending moment on the surface is expressed as

$$
M=4 r^{3} \sigma_{\max } \int_{0}^{\pi / 2}\left[(\operatorname{Sin} \theta)^{1+n}-(\operatorname{Sin} \theta)^{3+n}\right] d \theta
$$


where $\sigma_{\max }$ is the maximum surface tensile stress. The integration can be computed numerically by the Simpson rule and the maximum surface stress can be calculated, for a known hardening exponent $n$, as follows

$$
\sigma_{\max }=\frac{M}{4 r^{3} \int_{0}^{\pi / 2}\left[(\operatorname{Sin} \theta)^{1+n}-(\operatorname{Sin} \theta)^{3+n}\right] d \theta}
$$

\section{Experimental procedures}

The material used in this experimental investigation was austenitic AISI type 316 stainless steel (0.049C-0.54Si-1.36Mn-17.26Cr-11.20Ni-2.15Mo, wt\%) which was supplied by the Electric Power Research Institute in conjunction with the USA Nuclear Regulatory Commission in the form of $16 \mathrm{~mm}$ thick solution-treated hot rolled plates. The material was tested in the as-received condition, i.e., solution annealed at $1050^{\circ} \mathrm{C}$ for 30 minutes and then water quenched. Microstructural analysis showed an equiaxed austenitic structure with an average grain size of 40 microns [16]. In considering the nature of reverse bending tests, a simple specimen design is important. However the previously used rectangular bar [11,17] in bending experiments brings the problem of achieving a well-polished specimen surface; which is critical for carrying out a short crack study via replication. A rectangular bar can not be polished mechanically along its entire length, and requires an electropolishing method. As a result, a lot of polishing pits may occur within the material matrix. These pits in turn become favoured sites for first stage cracks to initiate and grow and subsequently influence the observation of cracks and the estimation of life. Therefore, a round-shaped specimen with a total gauge length of $153 \mathrm{~mm}$ and a diameter of 10 
mm was adopted in this study so that mechanical polishing was much easier, and obviated the introduction of electropolish pits. The cylindrical specimens were machined by fine turning and an allowance of $0.05 \mathrm{~mm}$ was left to permit polishing in order to get the final shape and dimensions of the working section. The polishing procedure mainly involved two steps. In the first step coarse polishing was accomplished by using emery papers with increasingly fine grit, i.e. 280, 400, 800 and 1,200 sizes. The second step was completed by cloth polishing using diamond pastes of 25, 6 and 1 microns respectively. A final scratch-free, mirror-finish surface was obtained.

The choice of a particular definition of failure is usually linked to the service application of the material but is also frequently influenced by experimental convenience. The definitions of failure commonly used at present include: (a) final fracture of the specimen into two pieces; (b) the observation of a certain size of crack; (c) a chosen percentage decrease in the value of the maximum stress; (d) a chosen percentage deviation of the curve of maximum stress versus cycles from the extrapolated cyclic hardening or softening behaviour; (e) the earliest identification of the formation of a cusp in the hysteresis loop. Final fracture of the specimen is the simplest and most frequent definition used in the past for reverse bending tests. However, for displacement or strain controlled bending tests, where there is a stress gradient, final fracture of the specimen may not occur for a long time, even though the specimen is badly cracked and unable to carry a significant load. The observation of a fatigue crack of a certain size has been used as a criterion of failure in some experiments [18], but under elevated temperature testing when the specimen is enclosed in a furnace, a certain size of crack is difficult to monitor continuously. The criterion of identification of a cusp in the hysteresis loop is relatively insensitive, 
because a cusp cannot be achieved with confidence until the cracked area has reached between $10 \%$ and $20 \%$ of the specimen section. The criterion that is probably among the more sensitive to the onset of significant cracking, and that most conveniently takes account of changes in the stress-strain response of the material due to strain hardening or softening is that contained in definition (d) above [19]. Therefore, a failure criterion of 5\% decay in the stabilised value of bending moment was used in these experiments. The type 316 stainless steel showed cyclic hardening at the beginning of the tests. This was followed by a period of slow but steady decay, which ended with a fast load decay due to macro-cracking. By drawing a straight line 5\% below and parallel to the steadily decaying line, the point of intersection of the parallel line with the eventual rapid load decay curve gives the creep-fatigue endurance $N_{f}[16]$.

The creep-fatigue tests were performed isothermally on the high temperature bending rig in air at $550^{\circ} \mathrm{C}$ under a fully reversed bending condition at a constant strain rate of $1 \times 10^{-3} s^{-1}$. Test strain ranges from $2.55 \%$ to $0.92 \%$ yielded lifetimes from 200 to 1,500 cycles respectively. A dwell period of 60 minutes was introduced at the condition of maximum cyclic strain with the help of the multifunction digital timer fitted in the rig. To collect crack growth data, replicas were taken throughout the creep-fatigue tests for each specimen by interrupting the tests, removing the top of the furnace and cooling down the specimen to room temperature, by using an air blowing fan. In order to assess the effect of a rest period introduced when taking replicas at elevated temperature, some additional continuous creep-fatigue tests were also performed at the same strain ranges as the interrupted tests.

The surface of the specimens was cleaned by acetone to remove loose oxides before taking the replicas. Then surface plastic replication on specimens in these tests was 
carried out using cellulose acetate sheet of 35 microns thickness, together with acetone spread over the specimen surface. The specimen remained in the rig for the whole duration of the test. The acetone causes replicas to wrap around the specimen by surface tension and no pressure is required. Each replica was left for about ten minutes to dry out completely, then removed from the specimen surface and mounted flat on a microscope glass slide for subsequent microscopical examination. In the tests large acetate strips with an area of $55 \mathrm{~mm} \times 20 \mathrm{~mm}$ were applied at both ends and in the middle along the gauge length of the specimens when the upper (tensile) surface was held under maximum strain. In this condition the cracks on the upper surface were fully open, and at the same time the cracks on the bottom compressive surface were closed. The whole area of both the upper and the lower surfaces of a specimen was covered by six replicas to collect all crack data. This is necessary in the case of bending tests as the bending moment is constant along the gauge length and therefore cracks are able to initiate and grow anywhere within the working gauge section. The same process was repeated at least twice in case of bubble formation under the acetate sheet, which could damage crack information on the replicas. The cracks on the replicas were measured from one tip to the other along the whole crack profile. Their length is defined as surface crack length $a_{s}$. This process was carried out by using an in-house REPAN image analysis system. This system consists of a high resolution metallurgical microscope, an image capturing monitor and a PC computer. 


\section{Experimental results}

\subsection{Strain-endurance}

All the tests were conducted above the fatigue limit of this material $\left(\Delta \varepsilon_{f l}=0.38 \%\right)$ with values of the total strain range being from $2.55 \%$ to $0.92 \%$ at $550^{\circ} \mathrm{C}$ with a one hour hold time in each cycle. These tests were continued until a 5\% change in the stabilised value of bending moment was detected. The total number of cycles at this point is defined as the creep-fatigue life of the specimens. Results from these creepfatigue tests are summarised in Table 1 . Regression of these test data in terms of angle of bend and bending moment gives the following power law equation:

$$
\Delta M=62.97(\Delta \phi)^{0.275}
$$

Similarly, a best-fit line can be obtained by regression of the test data in terms of maximum surface stress and total strain range:

$$
\Delta \sigma_{\max }=2831\left(\Delta \varepsilon_{t}\right)^{0.273}
$$

Regression of all data points yields the following Coffin-Manson equation in terms of inelastic strain range:

$$
\Delta \varepsilon_{\text {in }}\left(N_{f}\right)^{0.741}=0.919
$$


In the same way, by using the elastic strain range, the endurance curve can be represented by the following Basquin type equation:

$$
\Delta \varepsilon_{e}\left(N_{f}\right)^{0.186}=0.0188
$$

Equations (11) and (12) may be combined into a more useful endurance equation in terms of total strain range:

$$
\Delta \varepsilon_{t}=0.0188\left(N_{f}\right)^{-0.186}+0.919\left(N_{f}\right)^{-0.741}
$$

The results of continuous creep-fatigue tests, listed also in Table 1, show that the rest periods for taking replicas, which took about eight hours for each interruption including cooling and reheating, do not produce a significant effect on creep-fatigue life of specimens. It was also confirmed that these interruptions did not affect the fatigue life [20]. Therefore it is believed that the results of creep-fatigue tests with the replication process can be used to represent the real un-interrupted creep-fatigue condition in explaining changes of lifetime and crack growth behaviour.

\subsection{Crack growth behaviour}

Since a major surface crack at failure has been found to form by the linkage of many individually initiated minor cracks, its net length is defined as the sum of lengths of all individual minor cracks involved. For each specimen five dominant major cracks were measured separately. The number of minor cracks in each main crack and the number of minor cracks per unit length are displayed in Table 2. From these data it 
can be seen how the number of minor cracks changes with the changes in the total strain range. Comparing the crack growth curves of the longest major crack at each strain range, it shows that the final crack length tends to be longer with a decrease of strain range (Fig. 2).

The observations of minor crack growth indicate that minor cracks individually grow and subsequently coalesce, and their behaviour determines the overall behaviour of the major crack and also determines the life of specimens. The number of minor cracks varies with the change of number of cycles and a change of total strain range. Fig. 3 illustrates that the number of minor cracks contributing to a major crack first increases and then decreases with increasing number of cycles at $1.43 \%$ strain range. In fact, this indicates a two stage process of crack growth. In the first stage, individual minor cracks initiate and grow without linkage; this can be considered as first stage crack growth. In the second stage, these individual minor cracks have gradually grown long enough to meet each other, and the linkage process occurs and is enhanced with increasing number of cycles, so the number of minor cracks decreases until finally a major crack is formed from a certain number of minor cracks.

By plotting curves of number of minor cracks $\bar{n}$ against surface crack length $a_{s}$, a parabolic pattern is found similar to the curves of number of minor cracks versus number of cycles. This means that the number of minor cracks could be described by some mathematical equations in terms of surface crack length and strain range. Considering the number of minor cracks in five major cracks at each strain range, three curves can be deduced and described relative to the average number of minor cracks $n_{\text {ave }}$, maximum number of minor cracks $n_{\max }$ and minimum number of minor cracks $n_{\min }$ as a function of surface crack length $a_{s}$, i.e., 


$$
\begin{aligned}
& n_{\text {ave }}=A_{1}+B_{1} a_{s}+C_{1} a_{s}^{2} \\
& n_{\text {max }}=A_{2}+B_{2} a_{s}+C_{2} a_{s}^{2} \\
& n_{\text {min }}=A_{3}+B_{3} a_{s}+C_{3} a_{s}^{2}
\end{aligned}
$$

Thus, a series of parabolic equations can be obtained for the different strain ranges. The regressions of constants $A_{1}, A_{1}^{\prime}, A_{1}^{\prime \prime} \ldots . ; B_{1}, B_{1}^{\prime}, B_{1}^{\prime \prime} \ldots$. and $C_{1}, C_{1}^{\prime}, C_{1}^{\prime \prime} \ldots$. in equations (14) for different strain ranges produces a parabolic equation expressing the average number of minor cracks $n_{\text {ave }}$ as a function of surface crack length $a_{s}$ and total strain range $\Delta \varepsilon_{t}$. Similarly, the maximum number of minor cracks $n_{\max }$ and minimum number of minor cracks $n_{\min }$ also can be derived by the same method. In general, they are expressed as follows:

$$
n_{f\left(\varepsilon_{t}, a_{s}\right)}=f_{1}\left(\Delta \varepsilon_{t}\right)+f_{2}\left(\Delta \varepsilon_{t}\right) a_{s}+f_{3}\left(\Delta \varepsilon_{t}\right) a_{s}^{2}
$$

The regression curves of average, maximum and minimum numbers of minor cracks at $2.55 \%$ strain ranges from equations (17) are represented in Fig. 4b. A comparison of the maximum number of minor cracks clearly shows that the number of minor cracks increase and the crack length decreases as a result of increasing the strain range. 


\subsection{Crack morphology}

The processes of minor crack linkage on the tensile side of the specimens when forming major cracks are clearly illustrated in a series of photographs of Fig. 5 obtained by light microscopy. It demonstrates that these individual minor cracks initiate always on oxide patches, indicating that oxide damage may assist Stage I cracks to initiate. Only a few minor cracks initiate from inclusions. It is seen that the higher the total strain range, the higher the density of minor cracks. Following the whole process of crack growth it is found that most cracks, which are around the dominant crack, do not grow very much with an increase of creep-fatigue cycles and they keep within the range of a few grain sizes (see Fig. 5c-d). This result proves that microstructural barriers may play an important role in the current creep-fatigue tests although shielding effects from the dominant crack are also likely to be significant. As seen in Fig. 6, most cracks on the tensile side of the specimens initiate from grain boundaries. Cracks propagate along a zigzag path, generally following grain boundaries and occasionally propagating in transgranular form. A few wedge cracks were found ahead of some crack tips, as shown in Fig. 6, which may suggest that a creep effect is produced at the crack tips by the introduction of hold time.

Because the cracks on the compressive side were always closed either when the creep-fatigue tests were under a hold period, or when the tests were interrupted to take replicas, it was difficult to detect details of cracks on replicas taken on the compressive side. Carefully checking the replicas, especially the replicas taken at later stages of creep-fatigue life, it has been found that the cracks on the compressive side have a different morphology from the tensile side. Most cracks observed on replicas of the compressive side initiate from the matrix, and only a few of them appear to initiate from oxide patches. The majority of cracks on the compressive side are very 
short, generally of a length of one or two grain sizes, only a few grow a little longer. In contrast to the tensile side, most of the cracks on the compressive side initiate and grow transgranularly, and only very few initiate intergranularly (Fig. 7). Their depth is also within one or two grain sizes and these short, transgranular cracks generally have blunt ends.

\section{Discussion}

\subsection{Crack growth behaviours}

The initiation and growth behaviour of individual minor cracks in Stage I and their subsequent coalescence in Stage II is the dominant characteristic during the failure of these specimens under the current creep-fatigue bend tests. The process of crack linkage has been observed in a 316 stainless steel during continuous fatigue cycles at $550^{\circ} \mathrm{C}$ [15]. The curves of the number of minor cracks against the number of cycles $N$ are compared in Fig. 8a for fatigue and creep-fatigue cycles at $550^{\circ} \mathrm{C}$ under $0.92 \%$ strain range. An obvious increase of the number of minor cracks is seen to be due to hold time. This is in agreement with the results which demonstrated that the number of cracks increase both with dwell duration and strain range [21]. Also, all curves in Fig. 8a possess the parabolic pattern showing that individual minor crack growth and then coalescence occurs under fatigue and creep-fatigue cycles in the same way. As expected, plotting together the $a_{s}-N$ curves of both fatigue and creep-fatigue conditions at the same strain range of $0.92 \%$ (Fig. 8b) indicates an increase of crack growth rate and a decrease of life due to the effect of temperature and time dependence. 
As seen in Figure 6, most of the distributed surface cracks on the tensile side initiate and propagate along grain boundaries. Some research work has investigated crack morphology on the tensile side and the compressive side respectively of bending beams under creep-fatigue conditions [11,22]. Crack growth from the compressive side was transgranular, whereas for the tensile side, it was predominantly intergranular when testing two types of 316 steel plates. These results are in agreement with the present experimental results. Both outcomes indicate that creepfatigue in tension is more damaging than in compression because the intergranular long cracks on the tensile side continue to grow with creep-fatigue cycling while the transgranular short cracks on the compressive side remain within one to two grain sizes.

Crack interaction and subsequent coalescence on the tensile side of specimens is a feature of the short fatigue crack failure mechanisms in this study. Crack propagation due to coalescence under a certain loading state is strongly influenced by the microstructure of the material on the one hand and by the interaction of cracks on the other [23]. Kamaya et al. [24] proposed the influence of the interaction between multiple cracks on crack growth behaviour greatly depends on the relative position of the cracks. Also, the influence is strongest when the crack lengths are equal and decreases as the difference in crack length increases. If the difference in crack length is greater than a certain level the interaction is sufficiently small to allow the influence of interaction to be ignored. The critical ratio in crack lengths was shown to be related to the magnitude of offset between the two cracks. The greater the offset is, the greater the requirement for similitude in crack length for there to be interaction. Parallel collinear non-coplanar semi-elliptical cracks are very sensitive to crack-tip shielding [25]. Larger cracks shield the tips of smaller cracks from the applied stress 
until the latter become non-propagating [26]. The fatigue crack growth of larger cracks does not appear to be significantly affected by the presence of smaller cracks, which has been one of the features of these experimental results (Fig. 5c-d)). J. Stolarz [27] proposed the increase in surface crack length due to coalescence has no effect on crack growth rate until the crack reaches its equilibrium aspect ratio which occurs exclusively in the depth direction. It was also suggested for low cycle fatigue, that crack coalescence of this nature at the surface has no significant influence on the kinetics of fatal crack growth.

\subsection{Mechanisms of creep-fatigue failure}

Under creep-fatigue conditions, cycle lifetime is both time and cycle dependent. Such interactions may be "sequential" when an element of one type of deformation is followed by the other, or more commonly, "simultaneous" when both modes co-exist in a single stress (or strain) cycle [21]. Although actual components experience extremely complex temperature-strain-time profiles, it is usual to represent simultaneous interactions between fatigue and creep in the laboratory, as in this study, by strain controlled cycles which contain a dwell at peak levels of strain. Failure may either be "fatigue dominated", which usually involves the growth of a surface initiated fatigue crack, or it may be "creep dominated" when grain boundary cavities link and extend outwards, encountering fatigue cracks only close to final failure.

Examinations of longitudinal sections in this study (see Fig. 6) provide evidence that surface cracks on the tensile side play a significant role in failure. Most of these cracks initiate and propagate intergranularly. The crack path resulting from different strain ranges are similarly intergranular and tortuous, with only a few exceptions, in which transgranular propagation occurs. It is known that at elevated temperature, 
grain boundaries are regions of high defect concentration due to the mismatch of the contiguous crystal lattices [28]. Grain boundaries can also act as a site of stress concentration, and give rise to high local stress and plastic anisotropy. A feature of the hold time test in austenitic steels is that the stress is relaxed, and this results in creep damage occurring on grain boundaries. Only a few wedge cracks related to stress relaxation were found, but no round cavities were detected. Therefore, it can be concluded that under the current test conditions, failures were fatigue dominated. As seen in Fig. 5, most of the cracks on the tensile side initiate from oxide patches. Because grain boundaries and their environs are zones of chemical segregation and precipitates that have poor oxidation resistance, oxidation penetration along grain boundaries is usually faster than into the bulk material. This type of grain boundary oxidation may accelerate intergranular crack initiation and growth [29]. Therefore the main effect of oxidation is to accelerate crack initiation and Stage I crack growth, but has little influence on Stage II crack growth because it has been found that cracks are filled by oxides only near the surface (Fig. 6). Since the experiments were conducted at higher strain ranges and the longest testing time was less than $1500 \mathrm{~h}$ (about two months), it is understandable that the oxidation effect on Stage II crack growth in austenitic 316 steel is not significant. From the above analyses, the failure mechanism of creep-fatigue under the current testing conditions can be attributed to early crack initiation and easy grain boundary crack growth caused by stress relaxation, oxidation, and most importantly, by multiple minor cracks joining together.

\section{Conclusions}

(1) Details of the mechanical mechanism of the bending rig, the methods of strain measurement and the stress-strain analysis have been presented. 
(2) It is found that the initiation and growth behaviour of individual minor cracks during the first stage and their subsequent coalescence in the second stage are the dominant feature in the failure of specimens under creep-fatigue bending conditions at $550^{\circ} \mathrm{C}$ with $0.9-2.5 \%$ strain range. Increasing the strain range causes an increasing number of minor cracks and a promotion of the process of minor crack coalescence.

(3) The different crack morphology and crack length on the two sides of a specimen indicates that a compression-only dwell is much less dangerous than a tension-only dwell.

\section{References}

1 Maiya P. Mater. Sci. Eng A 1981;47:13.

2 Wareing J. Metall Mater Trans A 1977;8:711.

3 Brinkman CR, Korth GE, Hobbins RR. Nucl. Technol 1972;16:299.

4 Wareing J. In: Fatigue at High Temperature, Applied Science Publishers, London and New York, 1983. p. 135.

5 Forrest PG, Penfold AB. Engineering 1961;192:522.

6 Forrest PG, Armstrong KB. Inst. Mech. Engrs Joint Int. Conf. on Creep, London, 1963. p. 3-1.

7 Dawson RAT. Inst. Metals thermal and High Strain Fatigue Conf., London, 1967. p. 239.

8 Coles A. Inst. Metals thermal and High Strain Fatigue Conf., London, 1967. p. 270.

9 Hill GJ. Inst. Metals thermal and High Strain Fatigue Conf., London, 1967. p. 312.

10 Batt AD, Murphy MC, Stringer MB. Metals Technol 1978;5:405.

11 Wood DS, Banks P. Fatigue Fract. Engng. Mater. Struct. 1990;6:551.

12 Brown MW, Gao N, Miller KJ. Strength of Materials, 2000;32:502.

13 Gao N, Brown MW, Miller KJ. Fatigue Fract. Engng Mater. Struct, 1995;18: 1407. 
14 Gao N, Brown MW, Miller KJ. Fatigue Fract. Engng Mater. Struct, 1995;18: 1423.

15 Shaikh Z, Ph.D. Thesis, University of Sheffield, 1991.

16 Gao N, Ph.D. Thesis, University of Sheffield, 1994.

17 Adams WR, Stanley P. J. Phys. E. Sci. Instr., 1974;7:669.

18 Brown MW, Miller KJ. In: Symp. Biaxial/Multiaxial Fatigue, San Francisco, ASTM, 1982.

19 Thomas GB. High Temperature Fatigue Properties and Prediction, Elsevier Applied Science, London and New York, 1987. p. 261.

20 Navarro A, de los Rios E. R. Phil. Mag. 1988;57:37.

21 Plumbridge WJ. Fatigue Fract. Engng. Mater. Struct. 1987;10:385.

22 Plumbridge WJ, Priest RH, Ellison EG. In: Third Int. Conf. on Mechanical Behaviour of Materials, Cambridge, 1979. p. 129.

23 Meyer S, Diegele E, Bruckner-Foit A, Moslang A. Fatigue Fract. Engng. Mater. Struct. 2000;23:315.

24 Kamaya N, Totsuka N. Corrosion Science 2002;44:2333.

25. Soboyejo WO, Knott JF, Fatigue and Fracture of Engineering Materials 1991;14:37.

26 Stokes B, Gao N, Lee KK, Reed PAS. Metall Mater Trans A 2005;36:977.

27. Stolarz J. Mater. Sci. Eng A 1977;234-236:861.

28 Suh CM, Lee JJ, Kang YG. Fatigue Fract. Engng. Mater. Struct. 1990;13:487.

29 Plumtree A, Tang NY. Fatigue Fract. Engng. Mater. Struct. 1989;12:377. 
Tables and Figure Captions:

Table 1 Results of bending creep-fatigue tests

Table 2 The number of minor cracks at different strain ranges

Fig. 1 A schematic view of the mechanical mechanism of the bending rig.

Fig. 2 The development of the longest major crack for four different strain ranges.

Fig. 3 Growth and linkage behaviour of cracks associated with the development of five major cracks at $1.43 \%$ strain ranges.

Fig. 4 Regression curves of growth pattern of minor cracks at 2.55\% strain range (a), and maximum growth pattern of minor cracks at different strain ranges (b).

Fig. 5 Replica studies of minor crack linkage patterns for forming a major crack on the tensile-hold surface at $1.43 \%$ strain range.

Fig. 6 Intergranular crack morphology on tensile side of longitudinally sectioned specimens at $1.43 \%$ strain range.

Fig. 7 Transgranular crack morphology on compressive side of longitudinally sectioned specimen at $2.55 \%$ strain range.

Fig. 8 Growth pattern of minor cracks (a) and major cracks (b) with and without hold time at $0.92 \%$ strain range. 
Table 1 Results of bending creep-fatigue tests

\begin{tabular}{||c|c|c|c|c|c|c|c||}
\hline $\begin{array}{c}\text { Test } \\
\text { No. }\end{array}$ & $\begin{array}{c}\text { Range of } \\
\text { bending } \\
\text { moment }\end{array}$ & $\begin{array}{c}\text { Range of } \\
\text { total } \\
\text { strain }\end{array}$ & $\begin{array}{c}\text { Range of } \\
\text { inelastic } \\
\text { strain }\end{array}$ & $\begin{array}{c}\text { Range of } \\
\text { elastic } \\
\text { strain }\end{array}$ & $\begin{array}{c}\text { Range of } \\
\text { max. } \\
\text { surface } \\
\text { stress }\end{array}$ & $\begin{array}{c}\text { No. of } \\
\text { cycles to } \\
\text { failure }\end{array}$ & $\begin{array}{c}\text { Replicas } \\
\text { Y=Yes } \\
\text { N=No }\end{array}$ \\
\hline & $\Delta M$ & $\Delta \varepsilon_{t}$ & $\Delta \varepsilon_{\text {in }}$ & $\Delta \varepsilon_{e}$ & $\Delta \sigma_{\max }$ & $N_{f}$ & \\
\hline & $\mathrm{N}-\mathrm{m}$ & $\%$ & $\%$ & $\%$ & MPa & cycles & \\
\hline 1 & 146 & 2.49 & 1.76 & 0.73 & 1033 & 219 & $\mathrm{Y}$ \\
2 & 143 & 2.55 & 1.84 & 0.71 & 1009 & 190 & $\mathrm{Y}$ \\
3 & 139 & 2.03 & 1.41 & 0.62 & 985 & 291 & $\mathrm{Y}$ \\
5 & 126 & 1.43 & 0.84 & 0.59 & 889 & 523 & $\mathrm{Y}$ \\
6 & 110 & 0.92 & 0.41 & 0.51 & 781 & 1486 & $\mathrm{Y}$ \\
7 & 141 & 2.57 & 1.85 & 0.72 & 1045 & 189 & $\mathrm{~N}$ \\
8 & 111 & 2.07 & 1.41 & 0.66 & 997 & 267 & $\mathrm{~N}$ \\
\hline
\end{tabular}


Table 2 The number of minor cracks at different strain ranges

\begin{tabular}{|c|c|c|c|c|c|c|}
\hline $\begin{array}{l}\text { Total } \\
\text { strain } \\
\text { range }\end{array}$ & $\begin{array}{l}\text { Major } \\
\text { cracks }\end{array}$ & $\begin{array}{l}\text { Major } \\
\text { crack } \\
\text { length }\end{array}$ & $\begin{array}{c}\text { Maximum } \\
\text { number of } \\
\text { minor } \\
\text { crack }\end{array}$ & $\begin{array}{c}\text { Average } \\
\text { value of } \\
\text { maximum } \\
\text { number of } \\
\text { minor } \\
\text { crack }\end{array}$ & $\begin{array}{l}\text { Number of } \\
\text { minor } \\
\text { crack per } \\
\text { unit length }\end{array}$ & $\begin{array}{l}\text { Average of } \\
\text { number of } \\
\text { minor } \\
\text { crack per } \\
\text { unit length }\end{array}$ \\
\hline$\Delta \varepsilon_{t}$ & & $L$ & $\bar{n}_{\max }$ & & $\bar{n}_{\max } / L$ & \\
\hline$\%$ & & Microns & & & $(1 / \mathrm{mm})$ & $(1 / \mathrm{mm})$ \\
\hline \multirow{5}{*}{2.55} & 1 & 4270 & 45 & \multirow{5}{*}{38} & 10.54 & \multirow{5}{*}{10.77} \\
\hline & 2 & 3725 & 43 & & 11.54 & \\
\hline & 3 & 3368 & 36 & & 10.69 & \\
\hline & 4 & 3357 & 39 & & 11.62 & \\
\hline & 5 & 2861 & 27 & & 9.437 & \\
\hline \multirow{5}{*}{2.03} & 1 & 4955 & 30 & \multirow{5}{*}{30} & 6.055 & \multirow{5}{*}{7.394} \\
\hline & 2 & 4674 & 44 & & 9.414 & \\
\hline & 3 & 3825 & 27 & & 7.059 & \\
\hline & 4 & 3684 & 26 & & 7.058 & \\
\hline & 5 & 2980 & 22 & & 7.383 & \\
\hline \multirow{5}{*}{1.43} & 1 & 5441 & 27 & \multirow{5}{*}{20} & 4.962 & \multirow{5}{*}{4.721} \\
\hline & 2 & 5065 & 23 & & 4.541 & \\
\hline & 3 & 4462 & 19 & & 4.258 & \\
\hline & 4 & 3250 & 16 & & 4.923 & \\
\hline & 5 & 2844 & 14 & & 4.923 & \\
\hline \multirow{5}{*}{0.92} & 1 & 6127 & 14 & \multirow{5}{*}{13} & 2.285 & \multirow{5}{*}{2.948} \\
\hline & 2 & 4897 & 12 & & 2.451 & \\
\hline & 3 & 4192 & 15 & & 3.578 & \\
\hline & 4 & 4182 & 14 & & 3.348 & \\
\hline & 5 & 3901 & 12 & & 3.076 & \\
\hline
\end{tabular}




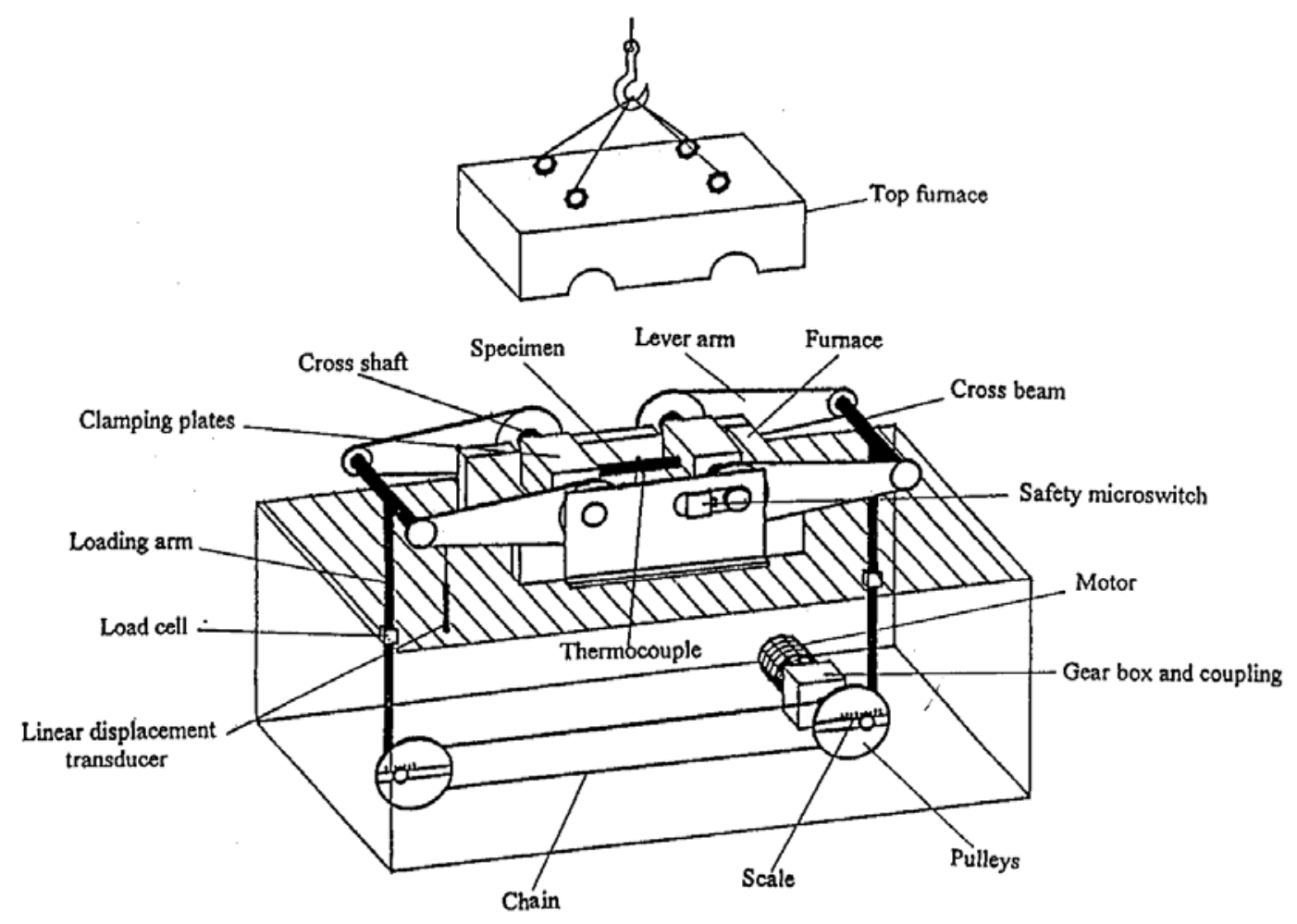

Fig. 1 A schematic view of the mechanical mechanism of the bending rig.

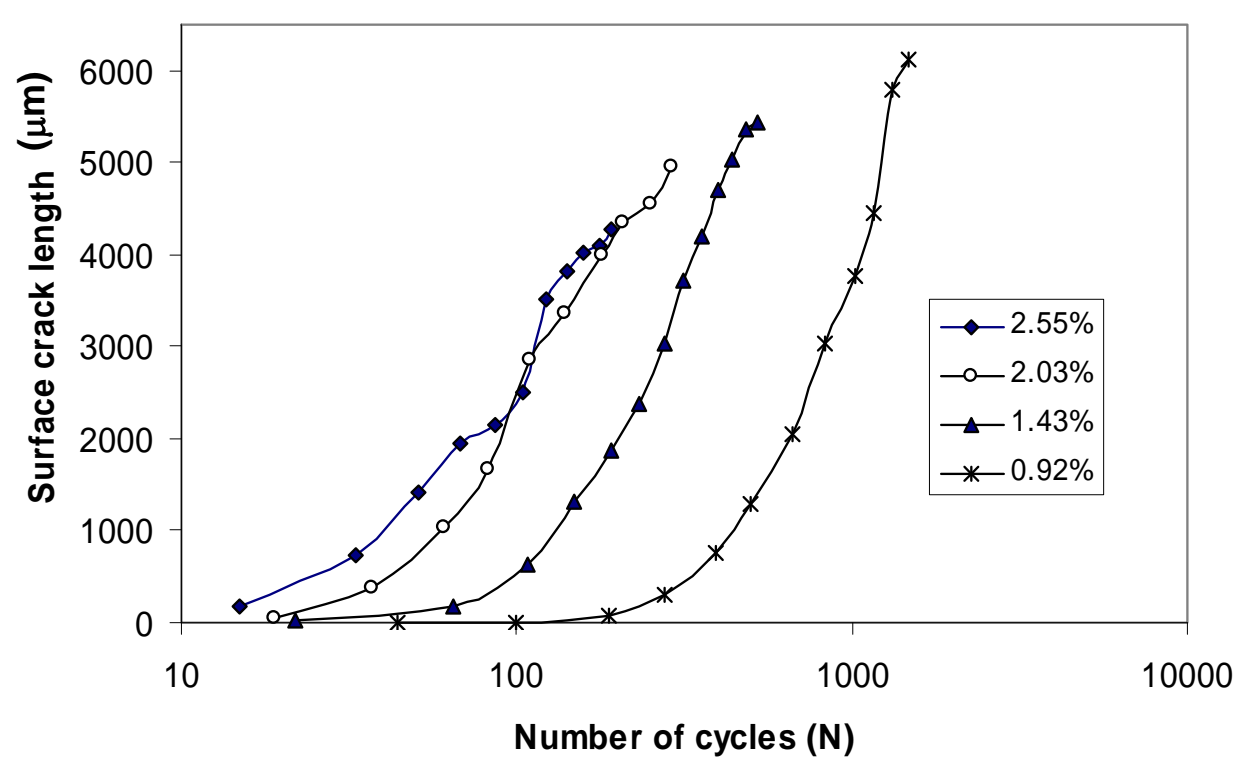

Fig. 2 The development of the longest major crack for four different strain ranges. 


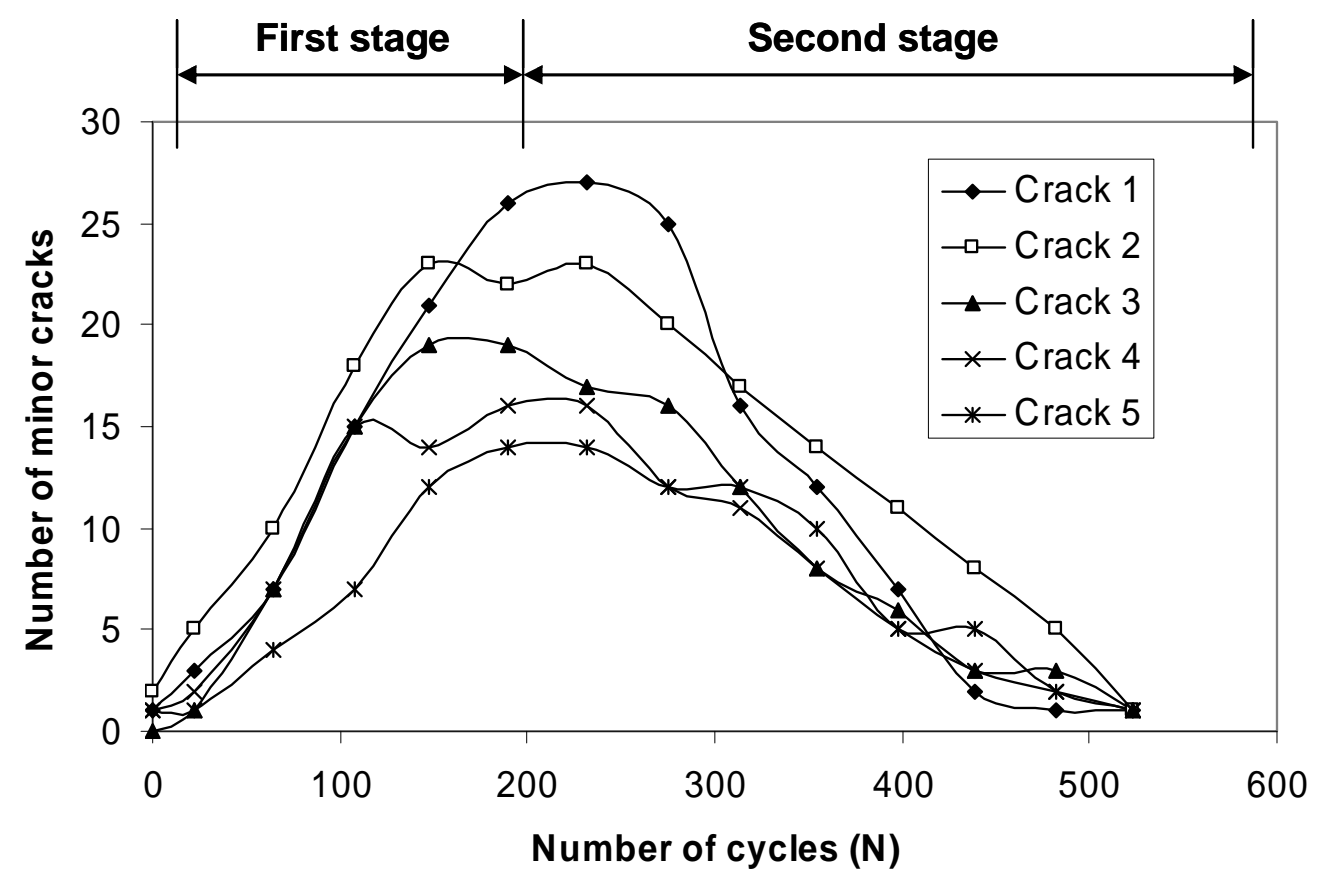

Fig. 3 Growth and linkage behaviour of cracks associated with the development of five major cracks at $1.43 \%$ strain ranges. 

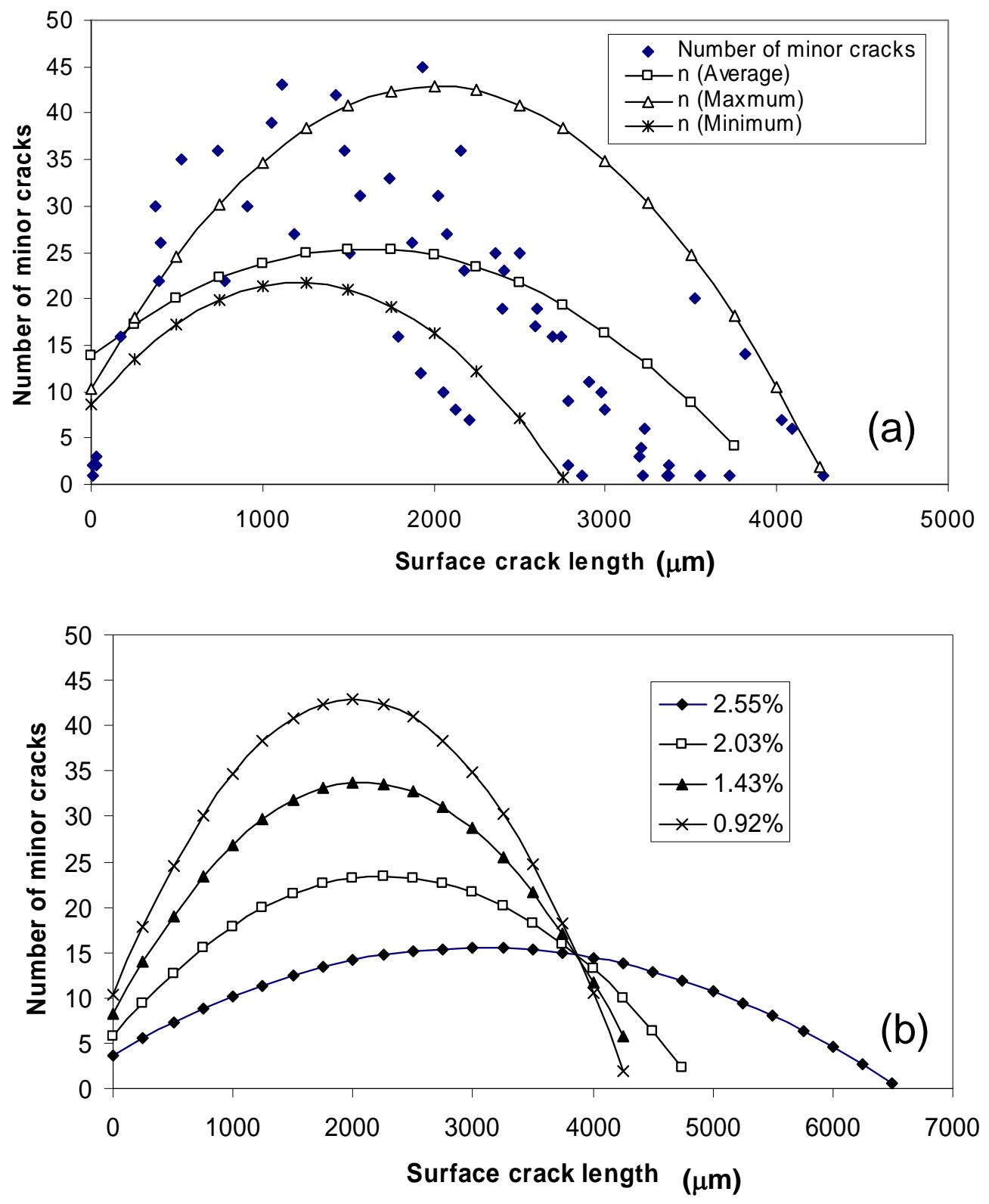

Fig. 4 Regression curves of growth pattern of minor cracks at 2.55\% strain range (a), and maximum growth pattern of minor cracks at different strain ranges (b). 


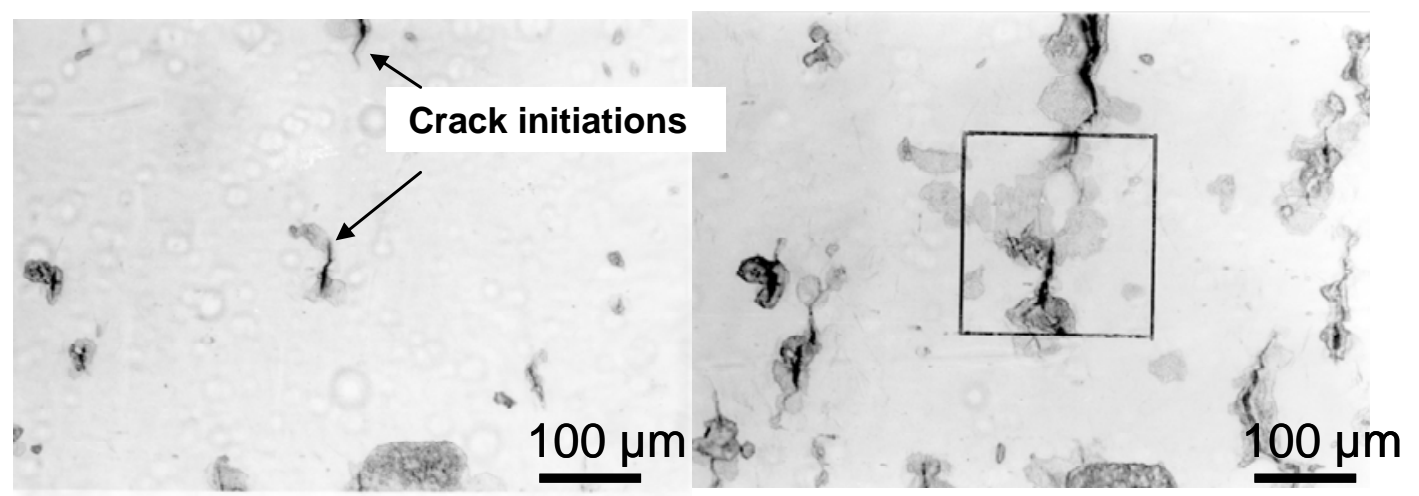

(a) $\mathrm{N}=108$ cycles, $\mathrm{N} / \mathrm{Nf}=0.21, \mathrm{n}=15$

(b) $\mathrm{N}=232$ cycles, $\mathrm{N} / \mathrm{Nf}=0.44, \mathrm{n}=27$

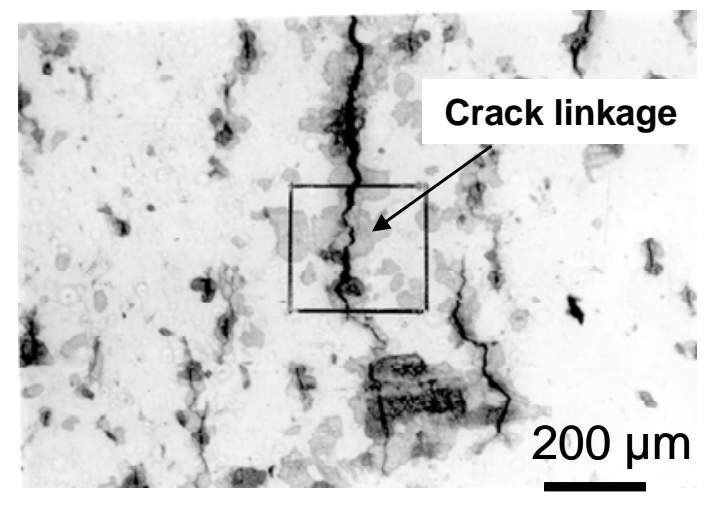

(c) $\mathrm{N}=314$ cycles, $\mathrm{N} / \mathrm{Nf}=0.60, \mathrm{n}=16$

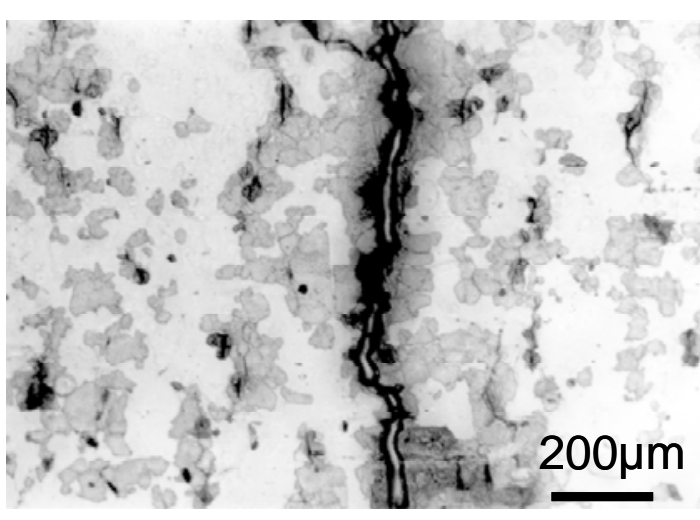

(d) $\mathrm{N}=523$ cycles, $\mathrm{N} / \mathrm{Nf}=1.0, \mathrm{n}=1$ stress direction

Fig. 5 Replica studies of minor crack linkage patterns for forming a major crack on the tensile-hold surface at $1.43 \%$ strain range. 


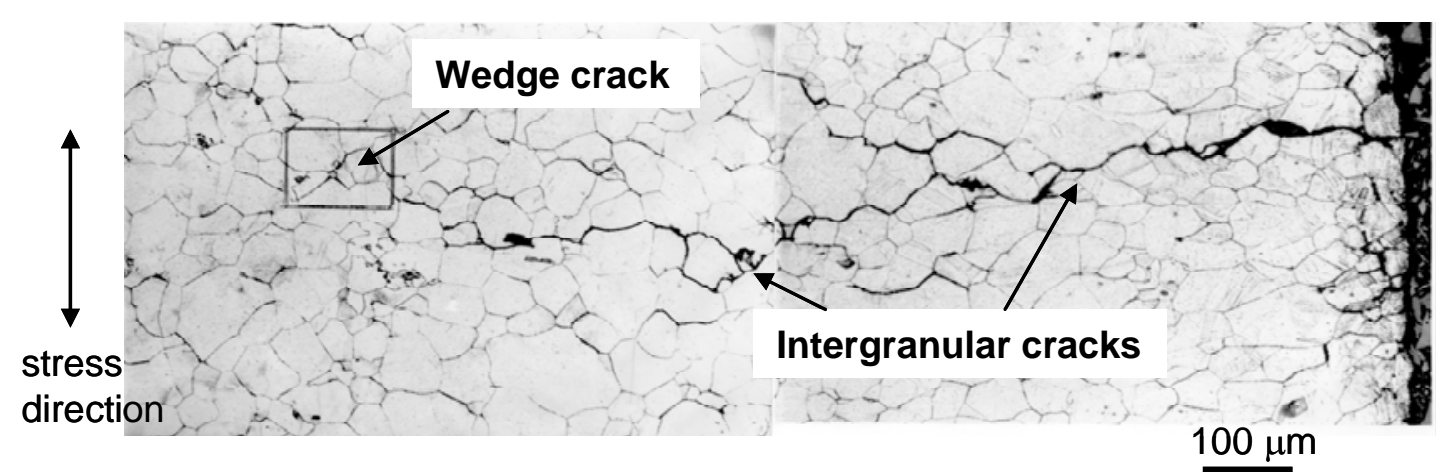

Fig. 6 Intergranular crack morphology on tensile side of longitudinally sectioned specimens at $1.43 \%$ strain range.

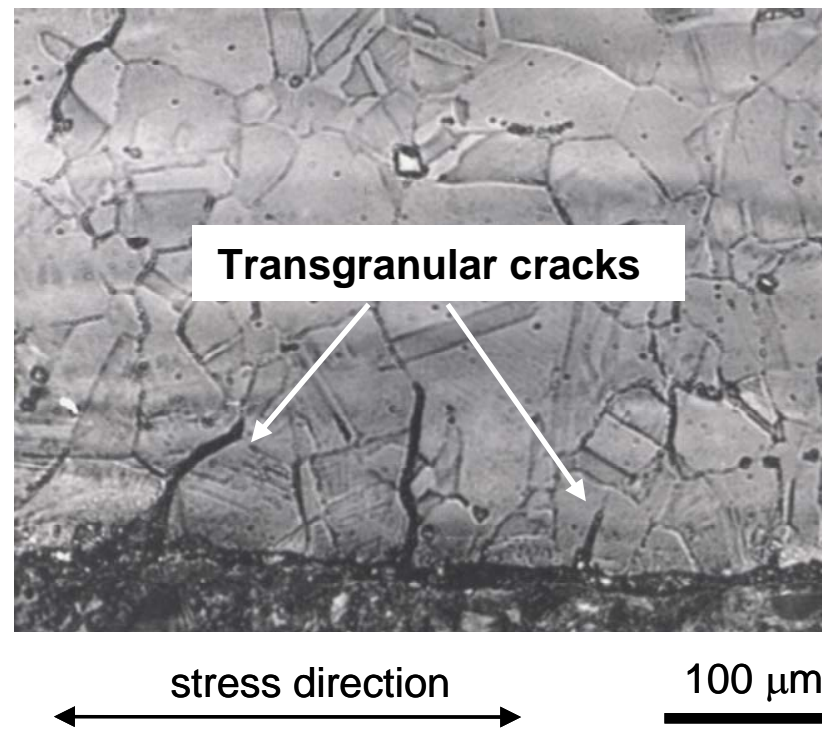

Fig. 7 Transgranular crack morphology on compressive side of longitudinally sectioned specimen at $2.55 \%$ strain range. 

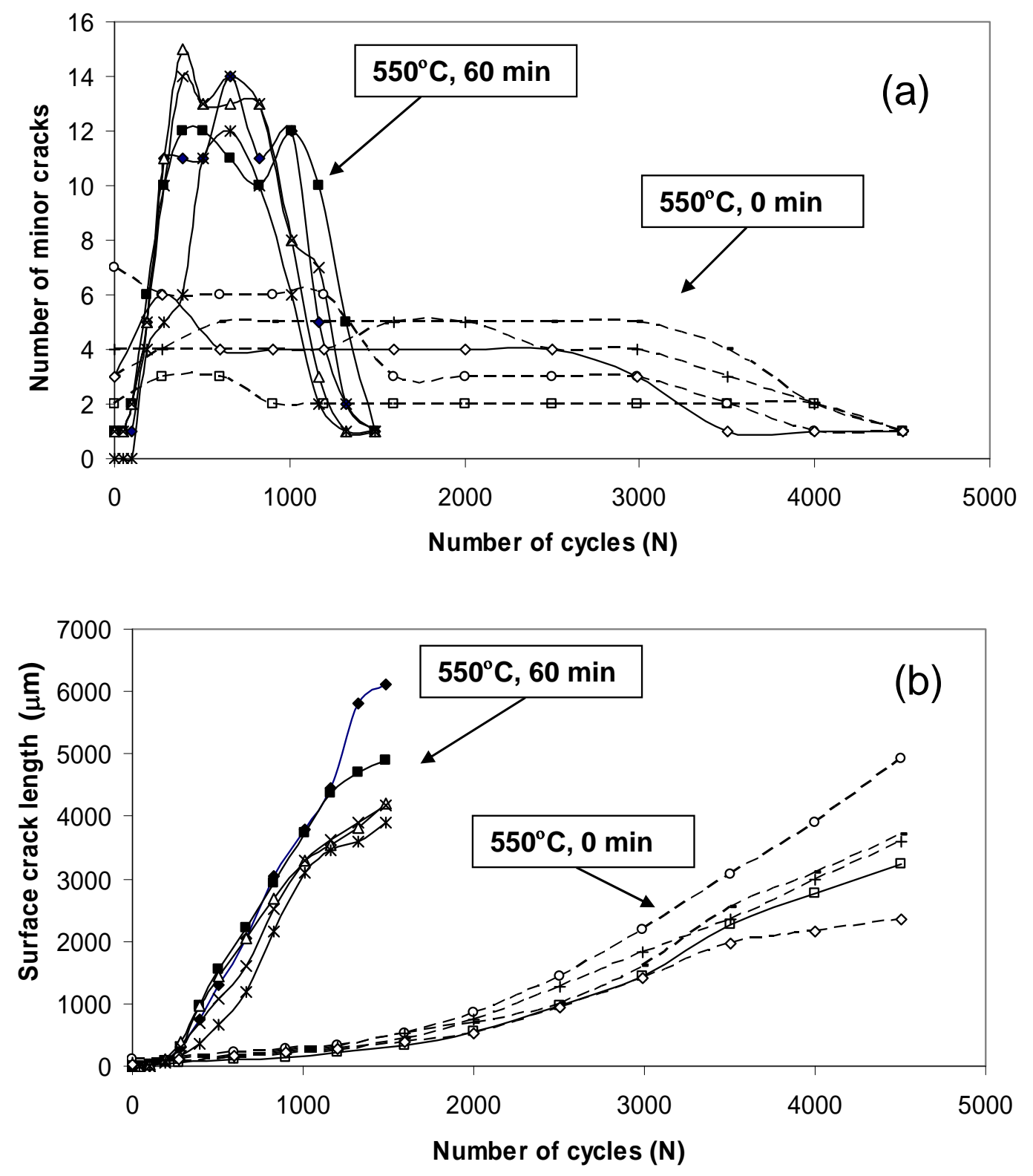

Fig. 8 Growth pattern of minor cracks (a) and major cracks (b) with and without hold time at $0.92 \%$ strain range. 